\title{
Chronic cranial window for photoacoustic imaging: a mini review
}

Yongchao Wang ${ }^{1,2}$ and Lei $\mathrm{Xi}^{2^{*}}$

\begin{abstract}
Photoacoustic (PA) microscopy is being increasingly used to visualize the microcirculation of the brain cortex at the micron level in living rodents. By combining it with long-term cranial window techniques, vasculature can be monitored over a period of days extending to months through a field of view. To fulfill the requirements of long-term in vivo PA imaging, the cranial window must involve a simple and rapid surgical procedure, biological compatibility, and sufficient optical-acoustic transparency, which are major challenges. Recently, several cranial window techniques have been reported for longitudinal PA imaging. Here, the development of chronic cranial windows for PA imaging is reviewed and its technical details are discussed, including window installation, imaging quality, and longitudinal stability.
\end{abstract}

Keywords: Photoacoustic imaging, Photoacoustic microscopy, Long term, Chronic, Cranial window

\section{Introduction}

\section{Cranial windows for longitudinal brain imaging}

As observed in practical cerebrovascular studies, the blood vessels are typically covered with a layer of skull bone, ranging in thickness from several hundred microns to a few millimeters, which is an enormous constraint in brain investigations [1-3]. In the early nineteenth century, the cranial window technique has been introduced for longitudinal brain imaging $[4,5]$. Especially with the development of optical imaging techniques, including but not limited to two-photon microscopy [6-14], laser speckle contrast imaging (LSCI) [15-24], and optical intrinsic imaging [25-33], an increasing number of cranial window techniques have been introduced and integrated with these imaging modalities for visualizing the microcirculation of the brain cortex over an extended period of months [3, 34-43]. For example, Morii et al. [34] established a glass-based imaging window to analyze the reactivity of rat pial vessels to adenosine and carbon dioxide. To visualize calcium in virally transfected striate cortical neurons in behaving monkeys, Heider et al. [44] developed a thin-silicone-based artificial dura for two-photon

\footnotetext{
* Correspondence: xilei@sustech.edu.cn

${ }^{2}$ Department of Biomedical Engineering, Southern University of Science and Technology, Shenzhen 518055, Guangdong, China

Full list of author information is available at the end of the article
}

imaging. In addition, Yedid and Bell [37], and Drew et al. [38] developed and improved the thin-skull technique in mice, allowing an extended period of imaging without causing an inflammatory response. Therefore, the cranial window provides a mature access method for a direct, longitudinal, in vivo study of brain functions (Fig. 1).

\section{Photoacoustic imaging for cerebrovascular visualization} Photoacoustic imaging (PAI) is a hybrid imaging modality that combines the deep tissue penetration capability of ultrasound imaging and the rich contrast and spectral features of optical imaging [45-53]. Generally, in PAI, the object is illuminated with short pulses or amplitudemodulated light, which thermally expands by absorbing and converting light energy into heat, simultaneously with the generation of acoustic waves. The amplitude of the generated acoustic pressure can be expressed as:

$$
P(\vec{r})=\eta \Gamma \mu_{a} F(\vec{r})
$$

Here $\eta$ is the conversion efficiency of the absorbed light energy that is converted into heat, $\Gamma$ is the Grüneisen parameter, $\mu_{a}$ is the absorption coefficient, and $F$ represents the local optical fluence.

The amplitude of acoustic pressure is proportional to the absorption coefficient, which is the source of the 


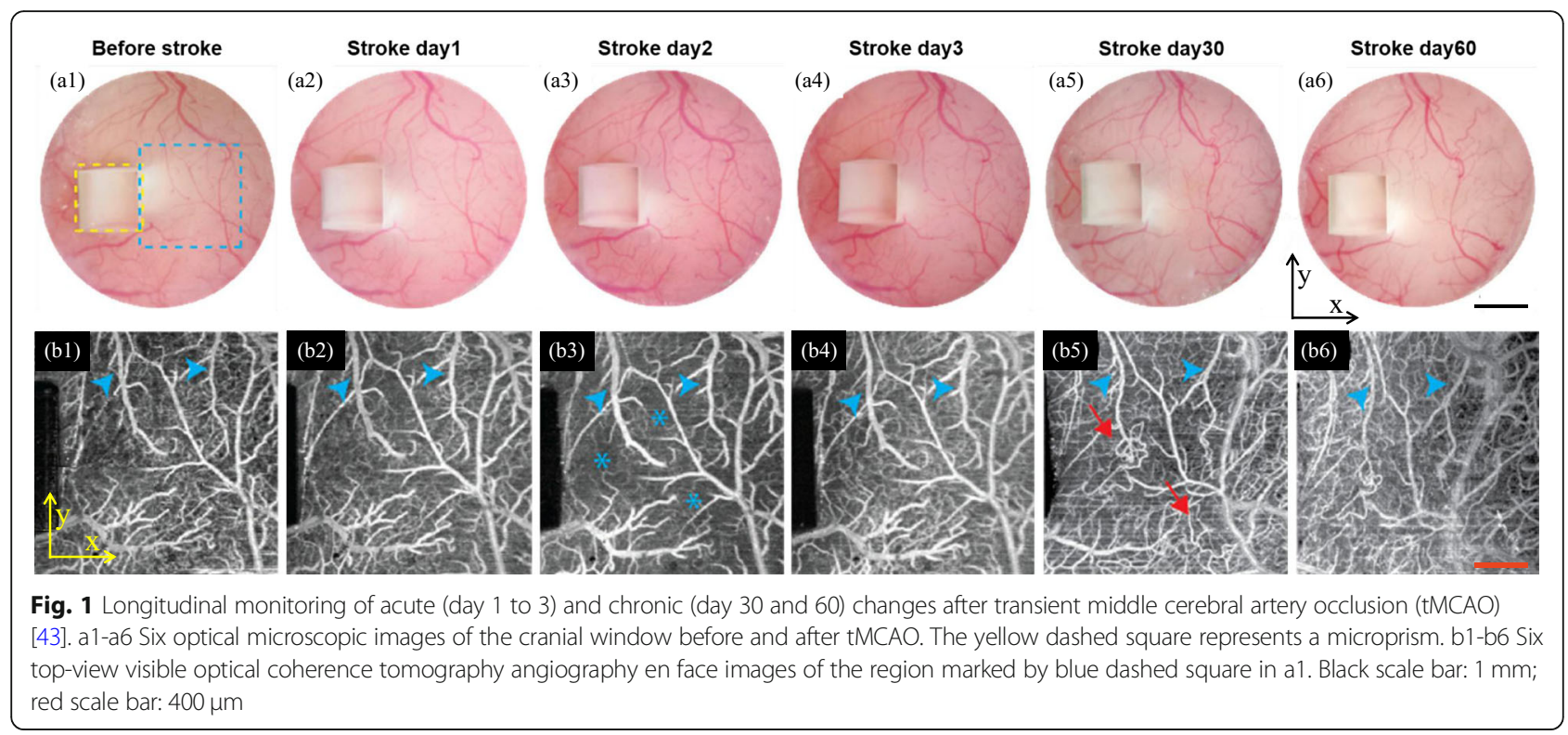

PAI contrast mechanism. Figure 2 shows the absorption coefficient spectra of various endogenous tissue chromophores [54]. Within the wavelength range of 400 to 600 $\mathrm{nm}$, PAI is extremely sensitive to both oxyhemoglobin and deoxyhemoglobin, proving its superior capability in vascular imaging. In the past decades, PAI has been utilized by numerous groups and has found comprehensive application in cerebrovascular imaging, including brain tumor model [55], epilepsy [56], ischemia-perfusion [57], Alzheimer's disease [58], stroke [59], and brain edema [60], enabling a better understanding of brain activities and functions (Fig. 3).

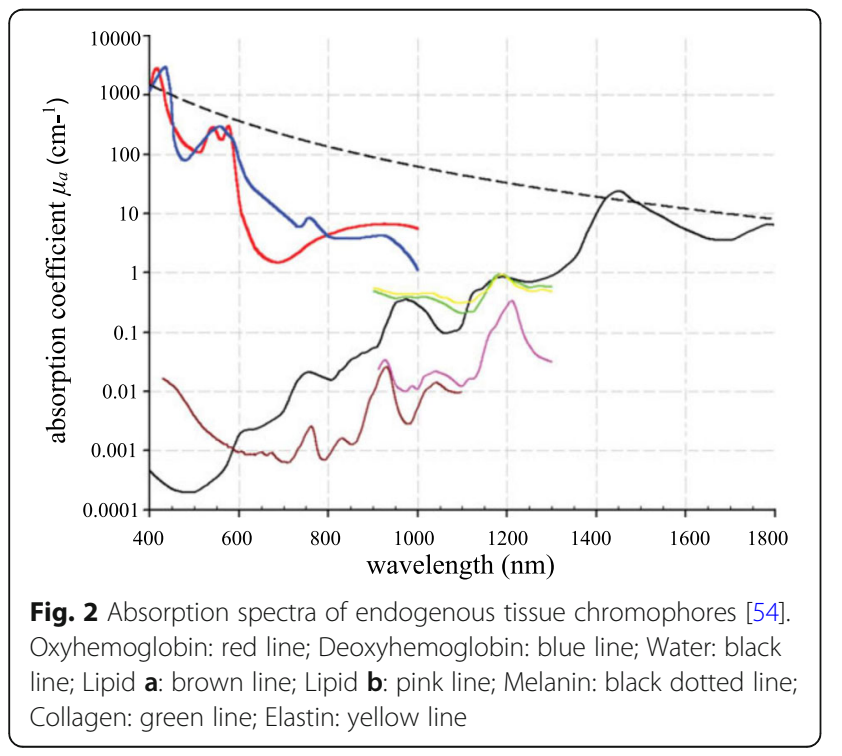

\section{Cranial windows for long-term PAI}

With the development and maturity of PA techniques, there is an urgent need for long-term PAI. Hence, investigations using the PA cranial window have attracted increasing attention in the previous decade. However, to date, only a few reports on the cranial window for longterm PAI, which is mainly limited by the window material, have been presented. In pure optical imaging modalities, the target is usually illuminated with a light source and the image is reconstructed by detecting the reflected or stimulated light. Therefore, the cranial window only needs to have sufficient optical transparency and biocompatibility. In contrast to the case in optical imaging, a PA image is obtained by detecting the light-induced acoustic signal, which may undergo prominent attenuation in case of acoustic impedance mismatches between the cranial window and brain tissues. Hence, the cranial window for PAI must simultaneously provide sufficient acoustic transparency. Several chemical and surgical methods have been proposed to overcome this challenge in the PA cranial window $[42,61,62]$.

\section{Skull window technique based on chemical penetration}

\section{Optical cleaning of skull window for PAI}

The optical cleaning technique has been widely applied to PAI to enhance imaging quality. Based on the principle of optical cleaning, the sample is usually infiltrated with high-refractive-index optical cleaning agents with improved optical scattering and acoustic impendence properties, enabling sufficient transmission of both light and the induced acoustic wave. For instance, Zharov et al. [63, 64] successfully combined this technique with PA flow 

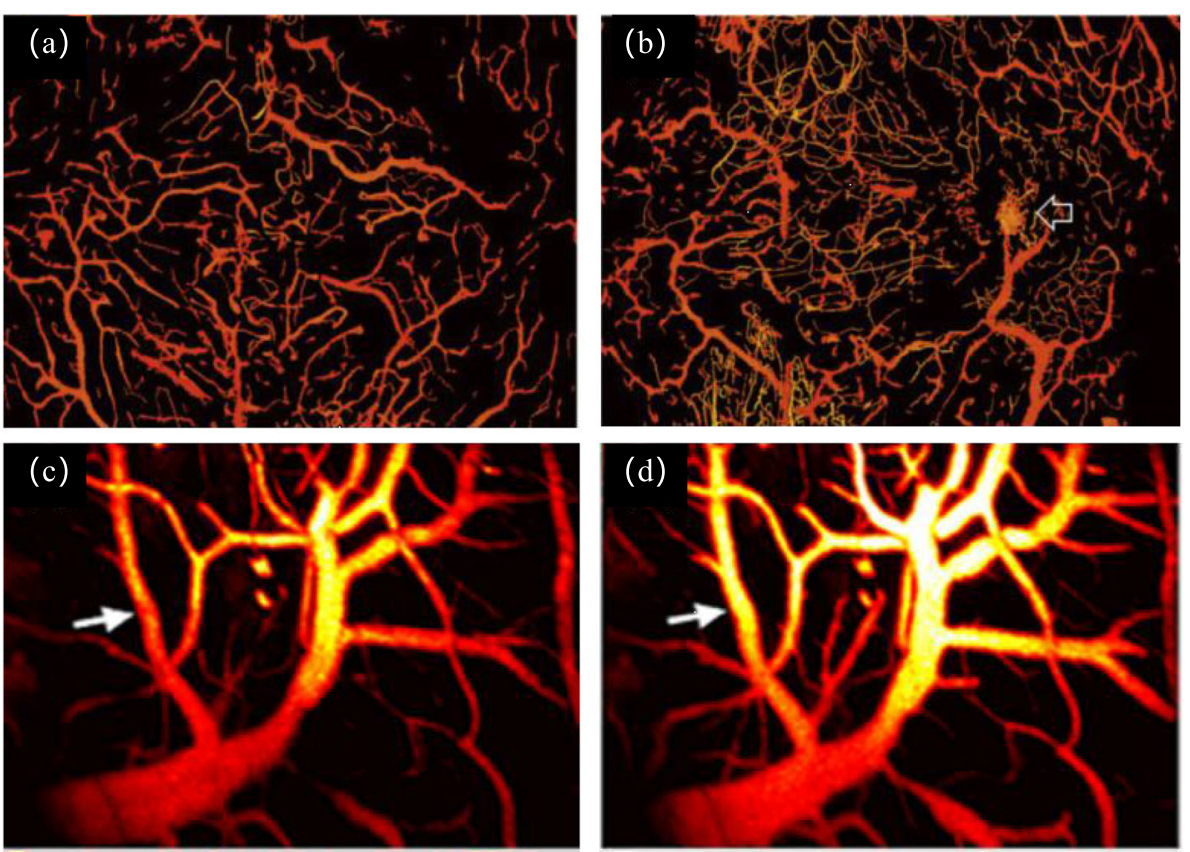

Fig. 3 In vivo imaging of cerebrovascular disease model using optical-resolution photoacoustic microscopy (OR-PAM). a, b PA images of normal and glioma mouse brains, respectively [55]. The tumor core is indicated by the arrow in b. c, d PA images of mouse brain under ischemia and perfusion, respectively [57]. The white arrows reveal an obvious change in diameter and intensity of a single vessel due to ischemia and perfusion

cytometry to improve the sensitivity and resolution for the detection of circulating tumor cells in deep blood vessels. Zhou et al. [65] demonstrated that a glycerol-water solution, a commonly used optical clearing agent in tissue optical clearing (TOC), could improve the imaging depth and lateral resolution of OR-PAM. However, all these studies focused on the optical cleaning of skin tissues and were not applied to the skull window for brain imaging.

In 2008, Genina et al. [66] first applied propylene glycol to the cranial bone in vitro, and the results revealed that both the absorption and scattering coefficients of the sample were reduced by $20 \%-30 \%$. In the following decade, the optical clearing technique for the skull was further improved and applied to in vivo long-term optical imaging. In 2012, Wang et al. [3] first applied an innovative skull optical clearing solution (SOCS) to living animals. The skull can rapidly become completely transparent with SOCS treatment, enabling high-resolution LSCI of cortical cerebrovascular region. In 2015, Zhang et al. [67] conducted a quantitative analysis of the optical cleaning efficiency of SOCS, demonstrating that the scatter coefficient of the skull was reduced three-fold after SOCS treatment. Based on the innovative SOCS, they further improved the concentration of several components, realizing a rapid and repeatable skull [68]. The results of both white-light and LSCI images revealed that the transparency of the skull was maintainable for $1 \mathrm{~h}$. Post treatment with physiological saline, the skull returned to its initial state. In addition, when the skull is retreated with SOCS, it gains transparency within 10 min, enabling repeated imaging of the cortex vasculature. In 2016, Yang et al. [61] first applied SOCS to enhance the PA image quality of cerebrovascular regions in living mice with intact skulls. They demonstrated that this agent can enhance the transmission of both light and acoustic waves in the skull in vitro. Figures $4(\mathrm{a}-\mathrm{c})$ depict the typical reflected images of the United States Air Force (USAF) target. The target region, initially visible to the eyes, becomes completely invisible when covered with an intact skull. Post treatment with SOCS for 25 mins, the skull becomes optically transparent, enabling clear visualization of the target. The quantitative analysis of the optical transmittance with the skull shows that the transmission efficiency is almost tripled after the application of SOCS. In addition, to evaluate the impact of the SOCS on the ultrasonic transmittance, Yang et al. also performed in vitro ultrasonic experiments by scanning a metal plate beneath the intact skull pre- and post-treatment. The quantitative analysis of the echo signal indicated that the ultrasonic transmittance can be increased 1.58 folds post treatment.

Furthermore, to evaluate the skull cleaning performance in living animals, the pre- and post-treatment imaging quality of the cerebral vasculature in mice with intact skull were compared in detail. As shown in Figs. $4(\mathrm{~d}-\mathrm{g})$, both the reflection and PA images revealed that the number of captured vessels increase significantly after SOCS treatment. The PA signal of selected blood 

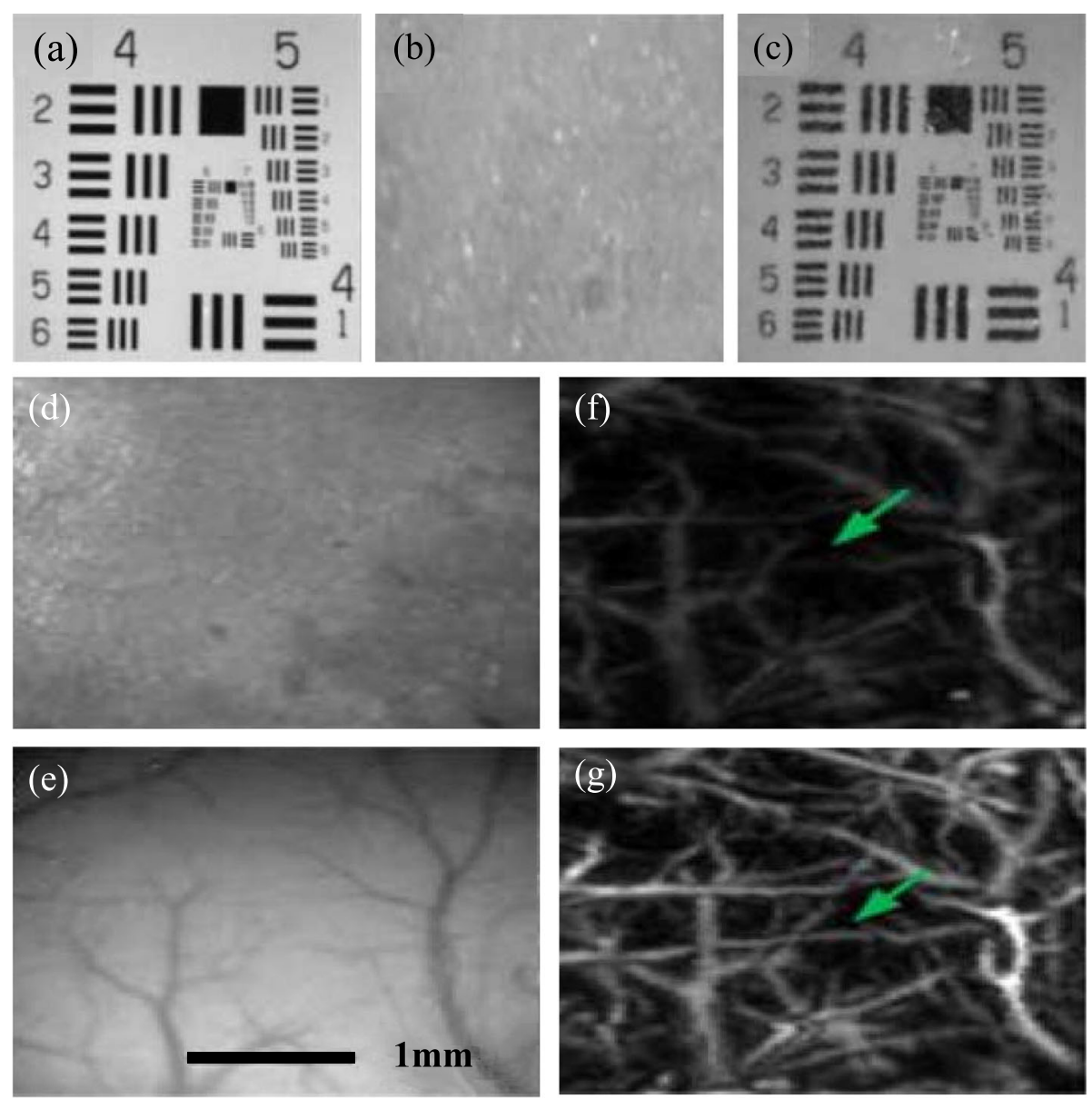

Fig. 4 The effect of SOCS on the skull in vitro and in vivo [61]. a-c Typical reflected images of the USAF target without and with the skull, and with SOCS-treated skull, respectively. Typical reflection images of cortical blood vessels obtained from untreated skull $\mathbf{d}$ and from the transparent skull after SOCS treatment for 25 mins e. Photoacoustic images obtained from intact skull $\mathbf{f}$ and from the transparent skull after SOCS treatment for 25 mins $\mathbf{g}$

vessels was also analyzed, which indicated that their average amplitude increased 2.59 folds, even up to 3.20 folds for a few vessels in the deep tissue. Therefore, it can be concluded that optical cleaning of the skull window can significantly enhance the acoustic-resolution photoacoustic microscopy performance in mice with intact skulls. Repeated treating of the skull enables longterm PA brain imaging in mice with enhanced quality.

\section{Craniotomy-based chronic cranial window}

Ultrasound-sensing chronic cranial window with softnanoimprinting

In the previous decade, optically transparent micro-ring resonator (MRR)-based ultrasonic detectors have been developed and integrated into PAI [69-71]. Although the MRR offers promising potential for chronic cranial window owing to its distinct optical transparency and miniaturized form factors, its application in in vivo studies remains unreliable because of the easy contamination of features, poor sensitivity, high cost, and low yield [69, 70]. In 2019, Li et al. [42] introduced an integrated transparent nanophotonic ultrasonic detector and successfully applied it to an ultrasound-sensing chronic cranial window. As shown in Fig. 5a, the ultrasonic detector comprises a glass window, MRR ultrasound detector, and optical fiber.

By fabricating an MRR ultrasonic detector with lowcost soft nanoimprint lithography using a polydimethylsiloxane (PDMS) mold, they optimized the preparation process, which greatly reduced the production cost. In addition, the sensitivity of the MRR detector was improved by more than 10 folds. Furthermore, they introduced a protective layer to shield the detector from potential contaminants by encapsulating it in a $5 \mu \mathrm{m}$ thick UV-curable PDMS thin film. The encapsulated MRR detector was exposed to physiological contaminants to evaluate its stability. As shown in Fig. 5(b), the optical resonance of the unprotected MRR decreased 


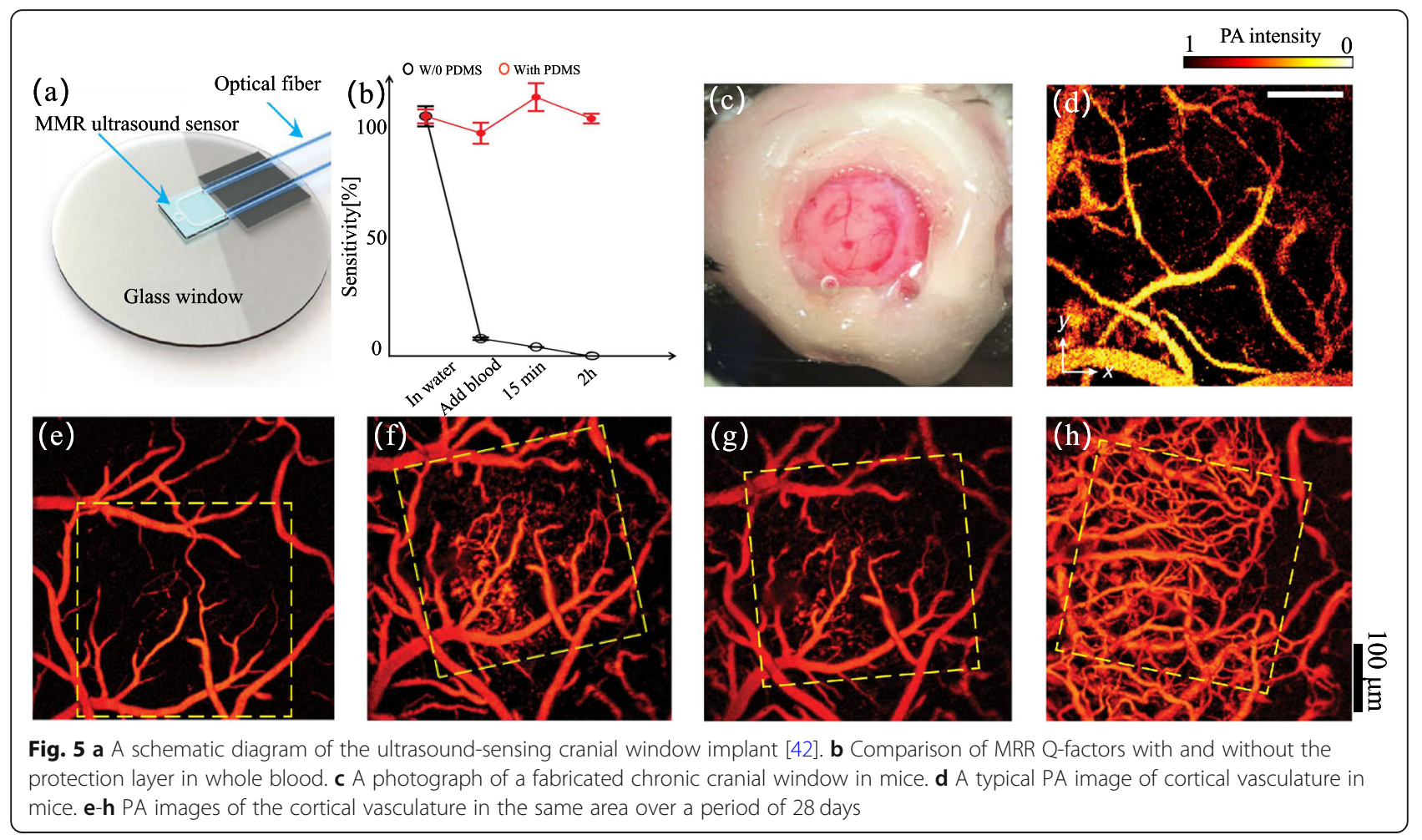

rapidly after being immersed in blood for 15 mins. In contrast, the encapsulated MRR showed no obvious change in detection sensitivity over $2 \mathrm{~h}$. These improvements make MRR more suitable for long-term PAI.

After investigating the performance of the MRR detector, Li et al. [69] first applied it to the PAI of the cortical vasculature in a living mouse brain with the skull removed. Figure 5(c) shows a photograph of a typical chronic cranial window fabricated with MRR. As shown in Fig. 5(d), combined with the MRR detector, PAM is suitable for visualizing the cortical vasculature with a high axial resolution of $3.57 \mu \mathrm{m}$. In addition, they performed longitudinal PAM imaging of cortical vasculature using a cranial window fabricated with a newly designed MRR detector. To evaluate the stability of the MRR detector in vivo, Figs. 5(e-h) present four PA images of the typical mouse brain at $0,7,14$, and 28 days postimplantation, which demonstrates that the Q-factor of the cranial window reduces marginally after 28 days. An obvious neovascularization process can be observed in the regions marked by yellow dashed boxes. These results confirm that the ultrasound-sensing chronic cranial window is suitable for long-term PAI.

\section{PDMS film-based chronic cranial window for PAM}

A previous investigation demonstrated that optically transparent PDMS film can be used as the cranial window for long-term optical imaging [40]. However, such a PDMS film is thick, which greatly attenuates the ultrasonic waves and prevents its direct use in PAI. To overcome the acoustic attenuation caused by the impedance mismatch between the brain tissue and the thick PDMS film, Wang et al. [62] introduced a newly designed PDMS-based cranial window implant allowing a large imaging area with a diameter of $5 \mathrm{~mm}$. As shown in Fig. 6(a), the cranial window implant was fabricated using a PDMS layer and a covering glass. They compared the cranial window imaging quality using different thicknesses, and demonstrated that the signal-noise ratio (SNR) can be decreased by $30 \%$ when the thickness of the PDMS film exceeds $400 \mu \mathrm{m}$. The chosen thickness of the PDMS layer (approximately $50 \mu \mathrm{m}$ ) was sufficiently thin for an effective transmission of the ultrasonic signal. Furthermore, considering the elastic deformation capability of the PDMS film, it was bonded with a glass ring via air plasma cleaning to avoid potential deformation and wrinkles.

To evaluate the stability of longitudinal PAI, a longterm window was fabricated in rats (Fig. 6(b)). Figure $7(a-d)$ shows four typical PA images of the cerebral vasculature of a rat brain captured at $0,1,2$, and 3 weeks post-implantation, which demonstrates that the cortical vasculature can be stably detected up to 3 weeks postimplantation. In addition, quantitative analyses of both total vascular number and signal background ratio also revealed the stability of this cranial window.

By integrating with a 3D-printed resin frame [Fig. 6(c)], the cranial window was successfully applied to 
(a)

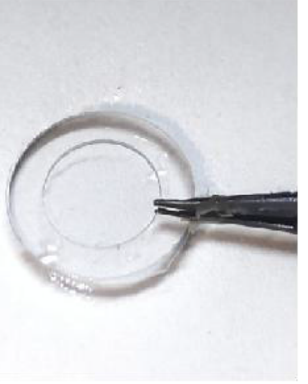

(b)

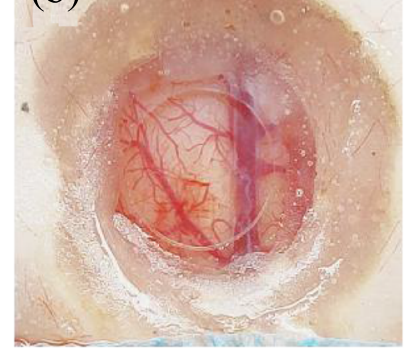

(c)

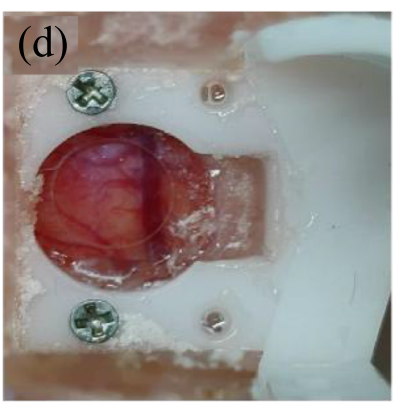

Fig. 6 a Photograph of the PDMS-based cranial window implant [62]. b A photograph of the cranial window for PA imaging in an anesthetized rat. $\mathbf{c}$ A photograph of the 3D-printed resin frame. $\mathbf{d}$ A photograph of the cranial window for PA imaging in a freely moving rat

brain imaging of freely moving rats [Fig. 6(d)]. Figure 7(e-h) show four typical PA images of the cerebral vasculature of a moving rat obtained at $0,4,8$, and 12 days post-implantation. The results indicate that the same brain region can be precisely monitored over a period of 2 weeks.

The imaging results in both anesthetized and freely moving rats revealed that the chronic cranial window provides an available method for long-term observation of cortical vasculature, offering promising opportunities for fundamental brain investigations. With this window model, various cerebral disorders, including stroke, epilepsy, brain tumors, and Parkinson's disease can be further investigated.

\section{Conclusion and discussion}

This paper reviews the reported cranial windows for longterm in vivo imaging of PAM. The scattering and attenuation of both light and ultrasound caused by the turbid skull usually result in inaccurate information on neuron activities or cerebral hemodynamics by severely reducing the resolution and SNR. Various chronic cranial windows have been fabricated to overcome the adverse effects of light caused by the skull, enabling researchers to perform longitudinal optical imaging [39, 40,43]. However, to the authors' knowledge, although these optical cranial windows will benefit PAM, which is based on the principle of all-optical detection, it does not compensate for the ultrasonic attenuation caused by the acoustic impedance
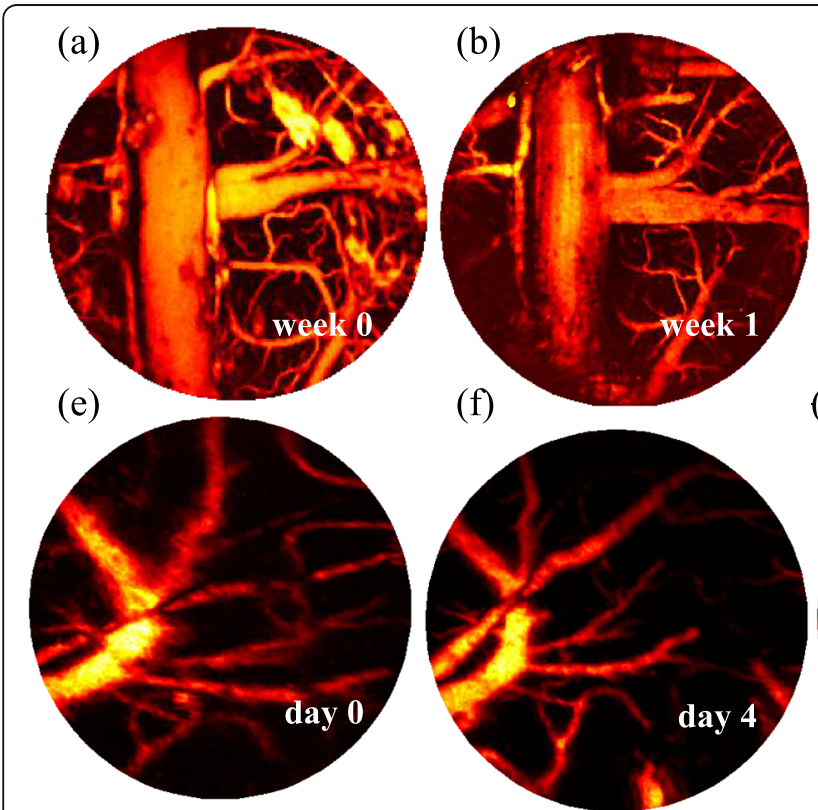

(f)

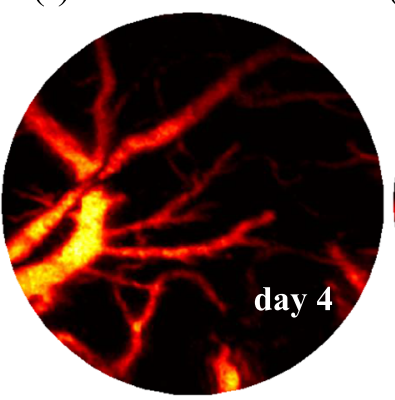

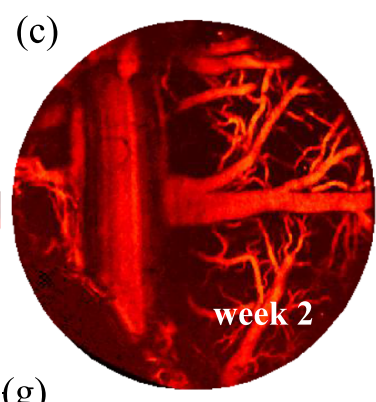

(g)

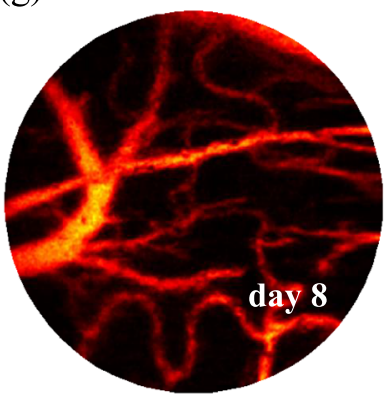

(d)

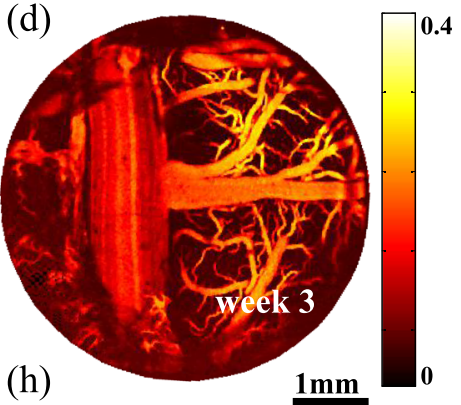

(h)

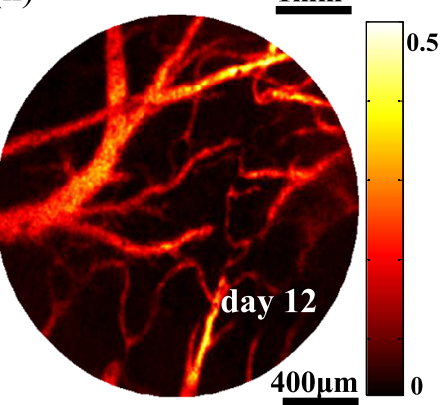

Fig. 7 Long-term in vivo PAl in both anesthetized and freely moving rats [62]. a-d Four typical PA images captured at 0, 1, 2, 3 weeks postimplantation in anesthetized rats. e-h Four typical PA images captured at 0, 4, 8, and 12 days post-implantation in freely moving rats 
Table 1 The systemic parameters of chronic cranial window for PAI

\begin{tabular}{lllllr}
\hline Cranial window technique & Group & Later resolution & Axial resolution & Imaging depth & Stability \\
\hline Optical cleaning of window & Yang et al. [61] & $45 \mu \mathrm{m}$ & $15 \mu \mathrm{m}$ & Approximately $3 \mathrm{~mm}$ & $>1 \mathrm{~h}$ \\
Ultrasound-sensing window & Li et al. [42] & Approximately $2.1 \mu \mathrm{m}$ & Approximately $3.6 \mu \mathrm{m}$ & - & 28 days \\
PDMS film based window & Wang et al. [62] & Approximately $10 \mu \mathrm{m}$ & Approximately $90 \mu \mathrm{m}$ & Approximately $0.8 \mathrm{~mm}$ & 21 days \\
\hline
\end{tabular}

mismatch at the window interface, preventing its broad application in PAI. Fortunately, inspired by these window techniques, several innovative chronic cranial windows have been proposed for long-term PAI [42, 61, 62]. Table 1 shows a detailed comparison of technical parameters, including the cranial window technique, lateral resolution, axial resolution, imaging depth, and stability. In this section, the current limitations and required improvements of the PA cranial window are discussed for further development.

Skull optical clearing, as an emerging cranial window technique, is derived from TOC, enabling scientists to image the cerebral hemodynamics with an intact skull using PAM [61]. However, further improvements are required to achieve better long-term imaging results in living animals. For example, although this technique can improve the ultrasonic transmission of the skull, to date it is only available for mice, which have a thin skull. Owing to the technique's non-ignorable ultrasound attenuation in thick skulls, further investigations should be performed in rats and other thick-skulled large animals. Moreover, the safety of the skull window technique should be taken into account if the SOCS produces inflammation of the cortex and damages the cerebral vasculature, even neurons. In addition, the skull window requires repetitive treatment to achieve long-term brain imaging. Further studies should be conducted to reduce the treatment time to avoid potential damage to the animals.

With regard to the ultrasonic-sensing chronic cranial window, an optically transparent MRR ultrasonic detector with a detection bandwidth of over $280 \mathrm{MHz}$ is used for long-term in vivo PAI in mice brains [42]. The axial resolution of this detector is up to $2.12 \mu \mathrm{m}$, and enables the researchers to obtain three-dimensional high-resolution images of the cerebral vasculature. However, investigation of this window technique is in still in the initial stages. The technique still faces the challenge of acoustic impedance mismatch between the window and brain tissue owing to the introduction of cover glass, which limits its application in PAM using ultrasonic transducers. Further studies should focus on realizing a broader application of this chronic cranial window. For instance, the MRR detector is ultrasensitive to disturbances from the external environment, and the stability of the MRR detector should be considered to obtain a high SNR image. Moreover, a larger field of view is required to enable the imaging of a wider range of cortical vessels. In addition, the fabrication of MRR detectors usually requires complex nanoimprint lithography processes.

The PDMS film-based chronic cranial window has excellent repeatability owing to the simple fabrication process of the implant [62]. In addition, by using a thin PDMS layer as the implant, the acoustic impedance mismatch between the brain tissue and implant can also be resolved, which enables its application to most existing PA microscopes. Although this cranial window has been proven to be suitable for PAI in both anesthetized and freely moving rats, further improvements should be considered. For instance, the window should be maintained for a longer time to enable long-term PAI.

In summary, the chronic cranial window technique, as an effective auxiliary tool, provides a better understanding of brain activity. Its continuous development and optimization will play an increasingly important role in brain investigations.

\section{Abbreviations \\ LSCl: Laser speckle contrast imaging; tMCAO: Transient middle cerebral artery occlusion; PAl: Photoacoustic imaging; PA: Photoacoustic; TOC: Tissue optical clearing; OR-PAM: Optical-resolution photoacoustic microscopy; PAM: Photoacoustic microscopy; SOCS: Skull optical cleaning solution; MRR: Micro-ring resonator; PDMS: Polydimethylsiloxane; SNR: Signal-noise ratio; USAF: United States Air Force}

\section{Acknowledgments \\ The authors are grateful to the University of Electronic Science and Technology of China, and Southern University of Science and Technology for permission to publish this research.}

\section{Authors' contributions}

All authors made substantial contributions to this manuscript. WYC wrote the first manuscript, and XL modified the final version of the manuscript. All authors discussed the results and implications of the manuscript at all stages. The authors have read and approved the final manuscript.

\section{Funding}

This study was supported by the National Natural Science Foundation of China, Nos. 62022037, 61775028, 81571722, 61528401; Department of Science and Technology of Guangdong Province, Nos. 2019ZT08Y191, SZBL2020090501013; Shenzhen Science and Technology ProgramNos. KQTD20190929172743294, JCYJ20200109141222892; and Startup grant from Southern University of Science and Technology.

\section{Availability of data and materials}

NA

\section{Declarations}

Competing interests

The authors declare no competing of interest. 


\section{Author details}

'School of Physics, University of Electronic Science and Technology of China, Chengdu 610054, Sichuan, China. 'Department of Biomedical Engineering, Southern University of Science and Technology, Shenzhen 518055 , Guangdong, China.

Received: 3 November 2020 Accepted: 27 April 2021

Published online: 26 May 2021

\section{References}

1. Marin G, Guerin C, Baillet S, Garnero L, Meunier G (1998) Influence of skull anisotropy for the forward and inverse problem in EEG: simulation studies using FEM on realistic head models. Hum Brain Mapp 6(4):250-269. https:// doi.org/10.1002/(sici)1097-0193(1998)6:4<250::aid-hbm5>3.0.co;2-2

2. Sakaguchi K, Furukawa S, Matsuo S, Sakashita N, Katsura T, Yamazaki K, Kawaguchi H, Maki A, Okada E (2009) Influence of a skull cranial window on the measurement of haemoglobin concentration in cortical tissue by multispectral imaging analysis. Opt Rev 16(2):74-80. https://doi.org/10.1007/s1 0043-009-0014-7

3. Wang J, Zhang Y, Xu TH, Luo QM, Zhu D (2012) An innovative transparent cranial window based on skull optical clearing. Laser Phys Lett 9(6):469-473. https://doi.org/10.7452/lapl.201210017

4. Donders FC (1850) De bewegingen der Hersenen en de veranderingen der vaatvulling van de Pia mater, ook bij gesloten onuitzetbaren schedel regtstreeks onderzocht. Nederlandsche Lancet 5:521-553

5. Forbes HS (1928) The cerebral circulation: I. observation and measurement of pial vessels. Arch NeurPsych 19(5):751-761. https://doi.org/10.1001/a rchneurpsyc.1928.02210110003001

6. So PT, Dong CY, Masters BR, Berland KM (2000) Two-photon excitation fluorescence microscopy. Annu Rev Biomed Eng 2(1):399-429. https://doi. org/10.1146/annurev.bioeng.2.1.399

7. Oheim M, Beaurepaire E, Chaigneau E, Mertz J, Charpak S (2001) Twophoton microscopy in brain tissue: parameters influencing the imaging depth. J Neurosci Methods 111(1):29-37. https://doi.org/10.1016/S0165-02 70(01)00438-1

8. Majewska A, Yiu G, Yuste R (2000) A custom-made two-photon microscope and deconvolution system. Pflugers Arch 441(2-3):398-408. https://doi.org/1 $0.1007 / \mathrm{s} 004240000435$

9. Helmchen F, Denk W (2005) Deep tissue two-photon microscopy. Nat Methods 2(12):932-940. https://doi.org/10.1038/nmeth818

10. Kobat D, Horton NG, Xu C (2011) In vivo two-photon microscopy to 1.6-mm depth in mouse cortex. J Biomed Opt 16(10):106014. https://doi.org/10.111 $7 / 1.3646209$

11. Del Bonis-O'Donnell JT, Page RH, Beyene AG, Tindall EG, McFarlane IR, Landry MP (2017) Dual near-infrared two-photon microscopy for deeptissue dopamine nanosensor imaging. Adv Funct Mater 27(39):1702112. https://doi.org/10.1002/adfm.201702112

12. Ávila FJ, Gambín A, Artal P, Bueno JM (2019) In vivo two-photon microscopy of the human eye. Sci Rep 9(1):10121. https://doi.org/10.1038/s41598-019-4 6568-z

13. Yamaguchi K, Kitamura R, Kawakami R, Otomo K, Nemoto T (2020) In vivo twophoton microscopic observation and ablation in deeper brain regions realized by modifications of excitation beam diameter and immersion liquid. PLoS One 15(8):e0237230. https://doi.org/10.1371/journal.pone.0237230

14. Beaulieu DR, Davison IG, Kılıç K, Bifano TG, Mertz J (2020) Simultaneous multiplane imaging with reverberation two-photon microscopy. Nat Methods 17(3):283-286. https://doi.org/10.1038/s41592-019-0728-9

15. Briers JD, Webster S (1996) Laser speckle contrast analysis (LASCA): a nonscanning, full-field technique for monitoring capillary blood flow. J Biomed Opt 1(2):174-179. https://doi.org/10.1117/12.231359

16. Briers JD (2007) Laser speckle contrast imaging for measuring blood flow. Opt Appl 37(1-2):139-152

17. Draijer M, Hondebrink E, van Leeuwen T, Steenbergen W (2009) Review of laser speckle contrast techniques for visualizing tissue perfusion. Lasers Med Sci 24(4):639-651. https://doi.org/10.1007/s10103-008-0626-3

18. Boas DA, Dunn AK (2010) Laser speckle contrast imaging in biomedical optics. J Biomed Opt 15(1):011109. https://doi.org/10.1117/1.3285504

19. Basak K, Manjunatha M, Dutta PK (2012) Review of laser speckle-based analysis in medical imaging. Med Biol Eng Comput 50(6):547-558. https:// doi.org/10.1007/s11517-012-0902-z
20. Wang J, Zhang Y, Li PC, Luo QM, Zhu D (2014) Review: tissue optical clearing window for blood flow monitoring. IEEE J Sel Top Quantum Electron 20(2):6801112-6801103. https://doi.org/10.1109/JSTQE.2013.22 86072

21. Milstein DMJ, Ince C, Gisbertz SS, Boateng KB, Geerts BF, Hollmann MW, van Berge Henegouwen MI, Veelo DP (2016) Laser speckle contrast imaging identifies ischemic areas on gastric tube reconstructions following esophagectomy. Medicine (Baltimore) 95(25):e3875. https://doi.org/10.1097/ MD.0000000000003875

22. Heeman W, Steenbergen W, van Dam GM, Boerma EC (2019) Clinical applications of laser speckle contrast imaging: a review. J Biomed Opt 24(8): 080901. https://doi.org/10.1117/1.JBO.24.8.080901

23. Kalchenko V, Sdobnov A, Meglinski I, Kuznetsov Y, Molodij G, Harmelin A (2019) A robust method for adjustment of laser speckle contrast imaging during transcranial mouse brain visualization. Photonics 6(3):80. https://doi. org/10.3390/photonics6030080

24. Potapova EV, Seryogina ES, Dremin W, Stavtsev DD, Kozlov IO, Zherebtsov EA, Mamoshin AV, Ivanov YV, Dunaev AV (2020) Laser speckle contrast imaging of blood microcirculation in pancreatic tissues during laparoscopic interventions. Quantum Elec 50(1):33-40. https://doi. org/10.1070/QEL17207

25. Grinvald A, Lieke E, Frostig RD, Gilbert CD, Wiesel TN (1986) Functional architecture of cortex revealed by optical imaging of intrinsic signals. Nature 324(6095):361-364. https://doi.org/10.1038/324361a0

26. MacVicar BA, Hochman D (1991) Imaging of synaptically evoked intrinsic optical signals in hippocampal slices. J Neurosci 11(5):1458-1469. https:// doi.org/10.1523/JNEUROSCI.11-05-01458.1991

27. Lu HD, Chen G, Cai JJ, Roe AW (2017) Intrinsic signal optical imaging of visual brain activity: tracking of fast cortical dynamics. Neurolmage 148:160168. https://doi.org/10.1016/j.neuroimage.2017.01.006

28. Chen JWY, O'Farrell AM, Toga AW (2000) Optical intrinsic signal imaging in a rodent seizure model. Neurology 55(2):312-315. https://doi.org/10.1212/ wnl.55.2.312

29. Chen SB, Li PC, Luo WH, Gong H, Zeng SQ, Luo QM (2006) Time-varying spreading depression waves in rat cortex revealed by optical intrinsic signal imaging. Neurosci Lett 396(2):132-136. https://doi.org/10.1016/j.neulet.2 005.11 .025

30. Ba AM, Guiou M, Pouratian N, Muthialu A, Rex DE, Cannestra AF, Chen JWY, Toga AW (2002) Multiwavelength optical intrinsic signal imaging of cortical spreading depression. J Neurophysiol 88(5):2726-2735. https://doi.org/10.11 52/jn.00729.2001

31. Juavinett AL, Nauhaus I, Garrett ME, Zhuang J, Callaway EM (2017) Automated identification of mouse visual areas with intrinsic signal imaging. Nat Protoc 12(1):32-43. https://doi.org/10.1038/nprot.2016.158

32. Tani T, Abe H, Hayami T, Banno T, Miyakawa N, Kitamura N, Mashiko H, Ichinohe N, Suzuki W (2018) Sound frequency representation in the auditory cortex of the common marmoset visualized using optical intrinsic signal imaging. ENEURO 5(2):ENEURO.0078-ENEU18.2018. https://doi.org/10.1523/ ENEURO.0078-18.2018

33. Liu XR, Hsiao TY, Li YQ, Chiu KS, Huang CJ, Li SJ, Lin CP, Zhao G, Sun CW (2020) Neurosurgical brain tumor detection based on intraoperative optical intrinsic signal imaging technique: a case report of glioblastoma. J Biophotonics 13(1):e201900200. https://doi.org/10.1002/jbio.201900200

34. Morii S, Ngai AC, Winn HR (1986) Reactivity of rat pial arterioles and venules to adenosine and carbon dioxide: with detailed description of the closed cranial window technique in rats. J Cereb Blood Flow Metab 6(1):34-41. https://doi.org/10.1038/jcbfm.1986.5

35. Masino SA, Kwon MC, Dory Y, Frostig RD (1993) Characterization of functional organization within rat barrel cortex using intrinsic signal optical imaging through a thinned skull. Proc Natl Acad Sci U S A 90(21):999810002. https://doi.org/10.1073/pnas.90.21.9998

36. Yuan F, Salehi HA, Boucher Y, Vasthare US, Tuma RF, Jain RK (1994) Vascular permeability and microcirculation of Gliomas and mammary carcinomas transplanted in rat and mouse cranial windows. Cancer Res 54(17):4564-4568

37. Yedid G, Bell G (2002) Macroevolution simulated with autonomously replicating computer programs. Nature 420(6917):810-812. https://doi.org/1 $0.1038 /$ nature 01151

38. Drew PJ, Shih AY, Driscoll JD, Knutsen PM, Blinder P, Davalos D, Akassoglou K, Tsai PS, Kleinfeld D (2010) Chronic optical access through a polished and reinforced thinned skull. Nat Methods 7(12):981-984. https://doi.org/10.103 8/nmeth.1530 
39. Goldey GJ, Roumis DK, Glickfeld LL, Kerlin AM, Reid RC, Bonin V, Schafer DP, Andermann ML (2014) Removable cranial windows for long-term imaging in awake mice. Nat Protoc 9(11):2515-2538. https://doi.org/10.1038/nprot.2014.165

40. Heo C, Park H, Kim YT, Baeg E, Kim YH, Kim SG, Suh M (2016) A soft, transparent, freely accessible cranial window for chronic imaging and electrophysiology. Sci Rep 6(1):27818. https://doi.org/10.1038/srep27818

41. Davoodzadeh N, Cano-Velázquez MS, Halaney DL, Jonak CR, Binder DK, Aguilar G (2018) Evaluation of a transparent cranial implant as a permanent window for cerebral blood flow imaging. Biomed Opt Express 9(10):48794892. https://doi.org/10.1364/BOE.9.004879

42. Li H, Dong BQ, Zhang X, Shu X, Chen XF, Hai RH, Czaplewski DA, Zhang HF, Sun C (2019) Disposable ultrasound-sensing chronic cranial window by soft nanoimprinting lithography. Nat Commun 10(1):4277. https://doi.org/10.103 8/s41467-019-12178-6

43. Beckmann L, Zhang X, Nadkarni NA, Cai Z, Batra A, Sullivan DP, Muller WA, Sun C, Kuranov R, Zhang HF (2019) Longitudinal deep-brain imaging in mouse using visible-light optical coherence tomography through chronic microprism cranial window. Biomed Opt Express 10(10):5235-5250. https:// doi.org/10.1364/BOE.10.005235

44. Heider B, Nathanson JL, Isacoff EY, Callaway EM, Siegel RM (2010) Twophoton imaging of calcium in virally transfected striate cortical neurons of behaving monkey. PLoS One 5(11):e13829. https://doi.org/10.1371/journal. pone.0013829

45. Beard PC (2002) Photoacoustic imaging of blood vessel equivalent phantoms. Proc SPIE 4618:54-62. https://doi.org/10.1117/12.469848

46. Wang LV (2009) Multiscale photoacoustic microscopy and computed tomography. Nat Photonics 3(9):503-509. https://doi.org/10.1038/nphoton.2 009.157

47. Hu S, Wang LV (2010) Photoacoustic imaging and characterization of the microvasculature. J Biomed Opt 15(1):011101. https:/doi.org/10.1117/1.3281673

48. Wang LV, Hu S (2012) Photoacoustic tomography: in vivo imaging from organelles to organs. Science 335(6075):1458-1462. https://doi.org/10.1126/ science. 1216210

49. Taruttis A, Ntziachristos $V$ (2015) Advances in real-time multispectral optoacoustic imaging and its applications. Nat Photonics 9(4):219-227. https://doi.org/10.1038/nphoton.2015.29

50. Weber J, Beard PC, Bohndiek SE (2016) Contrast agents for molecular photoacoustic imaging. Nat Methods 13(8):639-650. https://doi.org/10.1038/ nmeth.3929

51. Qi WZ, Jin T, Rong J, Jiang HB, Xi L (2017) Inverted multiscale optical resolution photoacoustic microscopy. J Biophotonics 10(12):1580-1585. https://doi.org/10.1002/jbio.201600246

52. Qin W, Jin T, Guo H, Xi L (2018) Large-field-of-view optical resolution photoacoustic microscopy. Opt Express 26(4):4271-4278. https://doi.org/1 0.1364/OE.26.004271

53. Chen Q, Guo H, Jin T, Qi WZ, Xie HK, Xi L (2018) Ultracompact highresolution photoacoustic microscopy. Opt Lett 43(7):1615-1618. https://doi. org/10.1364/OL.43.001615

54. Beard PC (2011) Biomedical photoacoustic imaging. Interface Focus 1(4): 602-631. https://doi.org/10.1098/rsfs.2011.0028

55. Alfano R, Shi LY (2019) Neurophotonics and biomedical spectroscopy. In: Bi RZ (ed) Chapter 8-optical-resolution photoacoustic microscopy of brain vascular imaging in small animal tumor model using nanosecond solidstate laser, pp 159-187. https://doi.org/10.1016/B978-0-323-48067-3.00008-1

56. Wang B, Xiang LZ, Jiang MS, Yang JJ, Zhang QZ, Carney PR, Jiang H (2012) Photoacoustic tomography system for noninvasive real-time threedimensional imaging of epilepsy. Biomed Opt Express 3(6):1427-1432. https://doi.org/10.1364/BOE.3.001427

57. Chen Q, Xie HK, Xi L (2019) Wearable optical resolution photoacoustic microscopy. J Biophotonics 12(8):e201900066. https://doi.org/10.1002/jbio.2 01900066

58. Tang YQ, Qian XJ, Lee DJ, Zhou QF, Yao JJ (2020) From light to sound: Photoacoustic and ultrasound imaging in fundamental research of Alzheimer's disease. OBM Neurobiol 4(2):1-21. https://doi.org/10.21926/obm. neurobiol.2002056

59. Hu S, Gonzales E, Soetikno B, Gong E, Yan P, Maslov K et al (2011) Opticalresolution photoacoustic microscopy of ischemic stroke. Proc SPIE 7899: 789906. https://doi.org/10.1117/12.874366

60. Xu Z, Zhu Q, Wang LV (2011) In vivo photoacoustic tomography of mouse cerebral edema induced by cold injury. J Biomed Opt 16(6):066020. https:// doi.org/10.1117/1.3584847
61. Yang XQ, Zhang Y, Zhao K, Zhao YJ, Liu YY, Gong H, Luo Q, Zhu D (2016) Skull optical clearing solution for enhancing ultrasonic and photoacoustic imaging. IEEE Trans Med Imaging 35(8):1903-1906. https://doi.org/10.1109/ TMI.2016.2528284

62. Wang YC, Liang GR, Liu F, Chen Q, Xi L (2021) A long-term cranial window for high-resolution Photoacoustic imaging. IEEE Trans Biomed Eng 68(2): 706-711. https://doi.org/10.1109/tbme.2020.3012663

63. Zharov VP, Galanzha El, Menyaev YA, Tuchin W (2006) In vivo high-speed imaging of individual cells in fast blood flow. J Biomed Opt 11(5):054034. https://doi.org/10.1117/1.2355666

64. Zharov VP, Galanzha El, Shashkov EV, Khlebtsov NG, Tuchin W (2006) In vivo photoacoustic flow cytometry for monitoring of circulating single cancer cells and contrast agents. Opt Lett 31(24):3623-3625. https://doi.org/10.13 64/OL.31.003623

65. Zhou Y, Yao JJ, Wang LV (2013) Optical clearing-aided photoacoustic microscopy with enhanced resolution and imaging depth. Opt Lett 38(14): 2592-2595. https://doi.org/10.1364/OL.38.002592

66. Genina EA, Bashkatov AN, Tuchin W (2008) Optical clearing of cranial bone. Adv Opt Technol 2018:267867-267868. https://doi.org/10.1155/2008/267867

67. Zhang Y, Zhang C, Zhong XW, Zhu D (2015) Quantitative evaluation of SOCS-induced optical clearing efficiency of skull. Quant Imaging Med Surg 5(1):136-142. https://doi.org/10.3978/j.issn.2223-4292.2014.12.02

68. Zhang C, Zhao YJ, Shi R, Zhu D (2016) A rapid and reversible skull optical clearing method for monitoring cortical blood flow. Proc SPIE 9707:970717. https://doi.org/10.1117/12.2210889

69. Li H, Dong BQ, Zhang Z, Zhang HF, Sun C (2014) A transparent broadband ultrasonic detector based on an optical micro-ring resonator for photoacoustic microscopy. Sci Rep 4(1):4496. https://doi.org/10.1038/ srep04496

70. Dong BQ, Li H, Zhang Z, Zhang K, Chen SY, Sun C, Zhang HF (2015) Isometric multimodal photoacoustic microscopy based on optically transparent micro-ring ultrasonic detection. Optica 2(2):169-176. https://doi. org/10.1364/OPTICA.2.000169

71. Zhang C, Chen SL, Ling T, Guo LJ (2015) Imprinted polymer microrings as high-performance ultrasound detectors in photoacoustic imaging. J Lightwave Technol 33(20):4318-4328. https://doi.org/10.1109/JLT.201 5.2466661

\section{Publisher's Note}

Springer Nature remains neutral with regard to jurisdictional claims in published maps and institutional affiliations.

\section{Submit your manuscript to a SpringerOpen ${ }^{\circ}$ journal and benefit from:}

- Convenient online submission

- Rigorous peer review

- Open access: articles freely available online

- High visibility within the field

- Retaining the copyright to your article

Submit your next manuscript at $>$ springeropen.com 